\title{
The effect of global warming to California water cycle
}

\author{
Yi Yang* \\ Department of Civil and Environmental Engineering, University of California-Davis, California, United State
}

\begin{abstract}
As global warming, climate variability becomes more and more extreme, and the frequency and intensity of extreme weather events are also increasing. Climate change has changed the hydrological cycle, and its change trend has put forward a severe test for the management of world water resources. Climate change has effects on several components of the water cycle, including precipitation, evapotranspiration, runoff, snow and snow cover, glaciers, and frozen soil. This essay analyses the vulnerability of California's various systems to climate change. California's water cycle model is particularly vulnerable to global climate change. In the past hundred years of California, the average precipitation has decreased with fluctuation; the average temperature has increased; extreme weather phenomena have occurred frequently; the evaporation of the water surface has decreased gradually; the temporal and spatial distribution of runoff has changed greatly; and glaciers have accelerated retreat. California's hydrological cycle is consistent with global water cycle change but also exhibits more complicated regional characteristics, with large spatial differences among watersheds.
\end{abstract}

\section{Introduction}

Global temperatures have risen, and this trend will continue. The water cycle is driven by climate variability in terms of its temporal role and spatiality. Energy and water, as two active factors in the climate system, are controlled by the water cycle at the same time. The water cycle is a vital component of the earth's material cycle. It transfers water, energy, and agrochemical substances throughout the earth system, thereby forming a global continuous and orderly dynamic system [1]. The water cycle connects the sea and land, shaping the surface morphology and having a profound effect on the formation, evolution, and development of the earth's surface structure. The core of the water cycle is transferring the material and energy which maintains the balance and coordination of the ecosystem by continuously delivering renewable freshwater resources [2]. As a result, the water cycle plays a major role in the evolution of the earth's surface structure and human sustainability.

At present, the world is facing more and more challenges from water problems, which include floods, droughts, and lack of access to clean water supply. There is an urgent need to monitor and manage the water cycle system according to the trend of global climate change, to deal with the problems of water resources in excess, scarcity or excessive pollution aspects [3]. The average temperature, average precipitation, glacier number and runoff in California have changed greatly since the middle and late 1990s. Based on the analysis of meteorological change data, this essay discussed the change trend and causes of the water cycle in California under the trend of global warming.

\section{California's climate}

\subsection{California meteorological conditions}

California is a state on the west coast of the United States, surrounded by the Pacific Ocean and encompassing 424,000 square kilometers. In 2020, California has about 40.12 million people and is the most populous state in the United States. Its gross social product (GSP) is \$2003 billion, accounting for $12.9 \%$ of the US gross domestic product (GDP). If it participates in the world ranking as a separate economic group, it is the ninth-largest economy in the world. The huge population and climate change also put great pressure on the environment of California. California's climate types are relatively diverse, according to geographic factors. To be more precise, the southern Sierra Nevada has a subtropical desert climate, the western coastal region has a Mediterranean climate, and the eastern Sierra Nevada has an alpine climate [4]. In recent summers, the Colorado Desert in the southeast has reached temperatures of over $54{ }^{\circ} \mathrm{C}$, which is comparable to the world's highest temperature; in winter, the Nevada highlands are as frigid as the Arctic. However, the temperature near the Pacific coast is typically between 32 and 0 degrees Celsius. Los Angeles and San Francisco have average temperatures of $18{ }^{\circ} \mathrm{C}$ and $14{ }^{\circ} \mathrm{C}$, accordingly. The northwest receives approximately 4420 $\mathrm{mm}$ of precipitation, the Colorado Desert receives between 50 and $75 \mathrm{~mm}$, and the Central Valley receives between 200 and $500 \mathrm{~mm}$. Therefore, climate change will have different effects on different regions of California. The complex terrain makes the fluctuation trend of

* Corresponding author: wxyyang@ucdavis.edu 
temperatures in California relatively dramatic, and the precipitation distribution becomes uneven.

\subsection{Climate change in California}

Climate change is already evident in some parts of California: the summer is getting hotter, the number of high-temperature days is increasing, the winter has become relatively warmer, the snow on the mountains melts earlier, and the sea level is rising. Climate change in California over the last century has been primarily reflected in temperature, precipitation, and extreme weather. In general, the surface temperature in California continues to rise, but there are obvious regional and seasonal variations; precipitation is declining significantly, and winter snowfall is significantly reduced. Additionally, severe precipitation and drought events are frequent. Extreme weather events such as high temperatures, heatwaves, flooding, and storms have increased in frequency and intensity.

\subsubsection{Temperature change}

According to the data from 1895 to 2020 released by the national climate data center of the National Oceanic and Atmospheric Administration, the yearly average temperature in California has increased by about 1.4 Fahrenheit in the past 126 years [5]. The data fluctuation is shown in Figure 1.

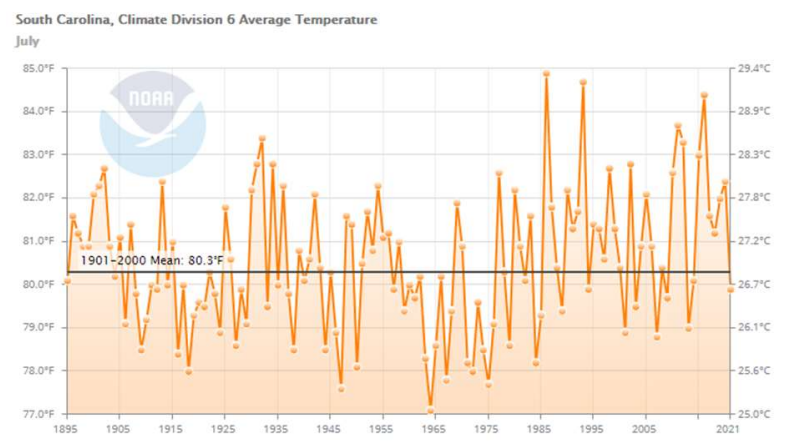

Figure 1. Annual average temperature and mean value in California from 1985 to 2020 (Department of Water Resources, 2020)

The annual hot weather may persist all summer due to the rise in temperatures. In 2100 , for example, the number of hot days in Los Angeles might rise from 15 to 96 days. In recent years, Sacramento has experienced temperatures of 101 degrees Fahrenheit or greater four times per year on average, with up to 25 times possible. California's water supplies will be severely impacted by rising temperatures. As the largest reservoir in California, Sierra snow mountain may reduce its water storage by one third by 2060 and a half by 2090 [6].

The increase in temperature will make the snow melt faster and more difficult to store and use. The picture taken in 2005 showed the appearance of the Sierra snow mountain (Figure 2.). Early snow melting combined with heavy rainfall may exacerbate problems between water supply, flood control, and hydropower, leading to a longer and more serious drought, and that is a potential hazard in California.

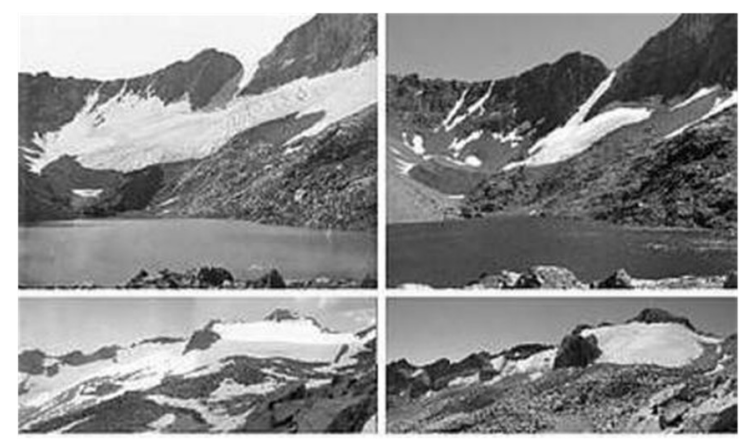

Figure 2. Photograph of Sierra Nevada glaciers in 2005 (MacDonald, 2007)

\subsubsection{Precipitation change.}

Climate change has accelerated the evaporation of water vapor on the earth's and ocean's surface, accelerating the water cycle and altering global precipitation patterns. Figure 3 shows the annual average precipitation of California from 1895 to 2020 [5]. As the precipitation curve reveals, the average annual precipitation in California varies considerably but generally follows a steady declining trend. Rainfall, rather than snow, is predicted to increase in the future, as will short-term high precipitation, putting a strain on California's water supplies. Between 2007 and 2009, the drought exacerbated California's already-scarce water supply and wreaked havoc on the lives of Californians. Almost all areas of California were classified as extreme drought and normal drought in the autumn of 2009. Some areas were classified as severe drought in January 2009. On March 30, 2011, Governor Jerry Brown announced the end of the drought, but the drought continued until December 2011. According to the data from the California Department of water resources, the drought from 2011 to 2013 is the twelfth consecutive drought period in the state's measurement records. The drought began in 2010 and lasted until the autumn of 2013. In early 2015, climate monitoring showed that most areas of California's Central Valley were moderately dry from January 2015 to April 2015 [7]. Drought monitoring in August 2020 showed that more and more serious droughts occurred in eastern California.

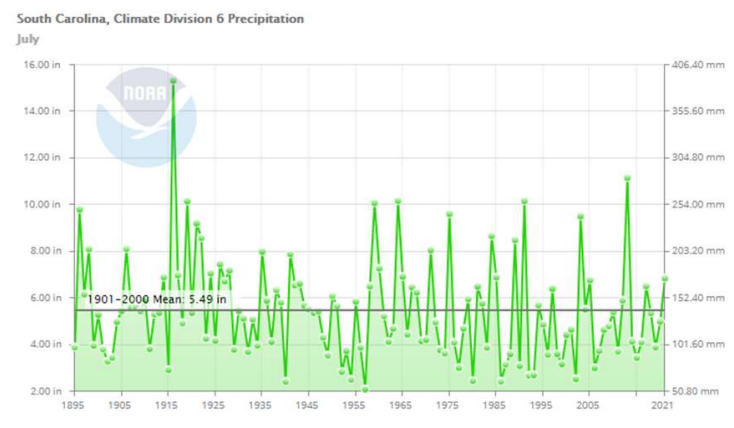

Figure 3. Annual precipitation and average value of California from 1985 to 2020 (Department of Water Resources, 2020) 


\subsubsection{Sea-level rise}

In the past century, the sea level in the coastal area of California has increased by about 7 inches. It is expected that the sea level will increase by 8-12 inches in 2050, compared with 2020. If the sea level rises by 16 inches, the San Francisco Bay area will face the risk of flooding. Simultaneously, the likelihood of saltwater invading coastal groundwater and entering the Sacramento San Joaquin Delta grows as a result of sea level rise. Many islands in the Sacramento San Joaquin sink 0.2 inches per year due to factors such as compaction, dehydration, wind corrosion, and oxidation. If sea level rise continues at its current rate, this region will soon be entirely submerged.

\subsubsection{Glacier melting}

Sierra Nevada glaciers rank sixth among the world's top ten melting glaciers. Sierra Nevada glaciers include parts of the Liput glacier, which is 16 miles north of Sequoia National Park in Tulare County. Liput glacier is the southernmost glacier in the United States. For more than a century, most glaciers in the Sierra Nevada have been monitored and photographed. Although many of these glaciers were expanding in the 1980s, now all glaciers are moving towards a steady retreat. Most of the smaller glaciers in the Sierra Nevada are located in the north or on the slope facing northeast, and the bright California sunlight can't directly contact them. However, rising temperatures will eventually ring the death knell of these southernmost glaciers in the United States.

\section{Causes of water cycle change in California}

Generally speaking, the vulnerability of regional systems is generally divided into natural ecosystem vulnerability and human social system vulnerability. The complex terrain structure and diverse climate types make the ecosystem of California more sensitive to adverse effects such as increased temperature, abnormal precipitation and sea-level rise caused by climate change. This situation contributes to a vicious cycle of California's water cycle, Thus, the natural ecosystem and social life system are more fragile.

\subsection{Evaporation acceleration}

The hydro-logical cycle includes evaporation, water vapor transport, precipitation, infiltration, runoff and other links, in which evaporation is a very important part. Intuitively, global warming makes surface water evaporate rapidly [8]. When evaporation accelerates, precipitation will increase and the warming Earth will become wetter. However, regional climate differences will lead to regional differences in temperature and precipitation response. According to the principle of water balance, the increase in evaporation will reduce runoff. Therefore, unnecessary evaporation should be reduced as much as possible in areas with relatively scarce water resources. However, the evaporation of arid and humid areas in California increases at the same time. Due to the special terrain and the obstruction of some mountain peaks, the water vapor formed by evaporation can not realize a large-scale virtuous cycle.

\subsection{Insufficient water supply}

\subsubsection{Precipitation reduction.}

The water cycle is a dynamic and well-organized system. According to system analysis, each connection in the water cycle is both a component and a subsystem of the system. Each subsystem is connected to the others by a network of inputs and outputs. Precipitation is the output of the atmospheric subsystem. However, California has been in a drought state for a long time in recent years, and the precipitation has decreased year by year, resulting in insufficient water cycle output and supply.

\subsubsection{Glacier recharge reduction.}

California's surface runoff is highly dependent on glaciers (snow). With the warming of the climate and the intensification of extreme climate and hydrological events, the change of glacier water resources will be more complex. Rivers supplied by glacier melt water with relatively developed glaciers may have high runoff fluctuations for a long time. For those watersheds with small areas and numbers of glaciers, under the increase in temperature, glaciers will retreat and glacier water resources will decrease. There will be an inflection point in glacier melting. The amount of glacier melt will decrease sharply, the glacier regulation function will decline, and the variation rate of river runoff will increase due to the influence of abnormal precipitation.

It is worth noting that for those watersheds with small areas and quantities of glacier, due to the limited share of glacier melt water, the impact of glacier water resources change on runoff is limited. Besides, the increase of runoff in the process of temperature rise is not obvious. But the impact of the glacier melting inflection point on glacier shrinkage or glacier disappearance can not be ignored.

\subsection{Reduction of vegetation coverage}

California has more trouble adapting to the loss of forests because of its current state of drought and tree loss. When the plant life living on the Earth's surface is taken away, the Lithosphere has a difficult time absorbing and capturing rainfall and groundwater, creating runoff and erosion in the area. The removal of forests also drastically increases the amount of carbon dioxide released into the atmosphere and affects multiple of its components, such as the hydrosphere [9]. Due to the influence of surface cover, especially vegetation, the water cycle also shows latitude or seasonal differences. Global warming may also have a negative impact on the ecological effects of arid areas. Many recent research results show that the reduction in vegetation coverage should be related to the 
changes in temperature, precipitation, and evaporation in arid areas. Since 1965, the precipitation in the arid area of California has decreased, while the temperature and evaporation potential have increased continuously, resulting in the loss of a large amount of soil water. This will result in the death of some shallow-rooted desert plants with weak drought resistance that rely on groundwater and soil water. Species diversity and vegetation coverage will also be reduced [10]. The decrease in vegetation coverage will change the runoff, destroy the vegetation, and remove the cover on the soil surface. Weakening the interception of plants to precipitation, more precipitation will form surface runoff, and the underground runoff will be reduced. And vegetation transpiration is also an important source of water vapour in the atmosphere. Therefore, due to the reduction of vegetation coverage in arid areas, the water cycle efficiency is reduced. When the time comes, the devastation will spread throughout the region and if these problems are still apart from California's resume, then the resilience after the natural disaster will be more difficult unless significant change and progress are made [11].

\section{Conclusion}

Under the weak action of vapor sinks in the arid areas of California, the change of climate and hydro logical elements has an important impact on the formation and change of temporal and spatial water resources. Global warming not only increases the frequency and intensity of extreme climate hydrological events, but also intensifies the hydrological fluctuation and uncertainty of water resources in California. Each part of the water cycle is significantly affected by the climate. The changes in precipitation reduction and temperature rise caused by greenhouse effects will cause significant changes in runoff, which will have a significant impact on the ecological and hydrological processes of California. The change of climate intensifies the instability of the system elements of the mountain water cycle. Under the influence of global warming, the water resource system based on mountain precipitation and glacier melt water supply in the majority of California's dry regions has become more vulnerable, significantly altering the state's natural water cycle process.

\section{References}

1. Hayhoe, K., Cayan, D., Field, C. B., Frumhoff, P. C., Maurer, E. P., Miller, N. L., ... \& Verville, J. H. (2004). Emissions pathways, climate change, and impacts on California. Proceedings of the national academy of sciences, 101(34), 12422-12427.

2. Vicuna, S., Maurer, E. P., Joyce, B., Dracup, J. A., \& Purkey, D. (2007). The sensitivity of California water resources to climate change scenarios 1. JAWRA Journal of the American Water Resources Association, 43(2), 482-498.

3. Dettinger, M. D. (2005). From climate-change spaghetti to climate-change distributions for $21 \mathrm{st}-$ century California. San Francisco Estuary and Watershed Science, 3(1).

4. Stine, S. (1994), Extreme and persistent drought in California and Patagonia during mediaeval time, Nature, 369(6481), 546-549.

5. Department of Water Resources (2020), The 19852020 California Drought: A review, California Department of Water Resources, September 2020.

6. MacDonald, G. M. (2007), Severe and sustained drought in southern California and the West: Present conditions and insights from the past on causes and impacts, Quat. Int., 173, 87-100.

7. Engineers take on drought in California. (2015, June 09). Retrieved March 13,2021,from https://magazine.engineer jobs.com/2015/engineers take on drought in California. Htm

8. Anderson, B. T. (2003), Tropical Pacific sea-surface temperatures and preceding sea level pressure anomalies in the subtropical North Pacific, J. Geophys. Res., 108(D23), 4732, doi:10.1029/2003JD003805.

9. Hertogh, T. (2020, November 22). Photo by Tomas Hertogh on Unsplash. Retrieved March 13, 2021, from https://unsplash.com/photos/eS6rqvLx7o0

10. Fried, J. S., Torn, M. S., \& Mills, E. (2004). The impact of climate change on wildfire severity: a regional forecast for northern California. Climatic change, 64(1), 169-191.

11. Mann, M. E., \& Gleick, P. H. (2015). Climate change and California drought in the 21st century. Proceedings of the National Academy of Sciences, 112(13), 3858-3859. 